Jap. J. M. Sc. \& Biol., 9, 71-79, 1956

\title{
COMPARISON OF INFECTION TYPES WITH RESPIRATORY PATTERNS IN SALMONELLA
}

\author{
Hisao UETAKE ${ }^{1)}$ AND ToshIKAZU MAKINO2) \\ Department of Micribiology, Sapporo Medical College, Sapporo ${ }^{3)}$
}

(Received: April 30th, 1956)

Broadly speaking, the type of Salmonella infections is either a gastroenteric or a typhoidal and septicemic disease. In rare instances the food-poisoning phase progresses on to the gastroenteric and eventually to the typhoidal or septicemic type of the disease. In men, a few species, such as $S$. typhi, S. paratyphi $A, B$ and $C$ give rise to a disease characterized by a fairly long incubation period and the predominance of septicemic, over intestinal symptoms. The great majority of the Salmonella species, however, produce gastroenteritis of the food-poisoning type in children and adults, or acute enteritis in infants characterized by a short incubation period and the predominance of intestinal, over septicemic symptoms.

In typhoid type of infection, Salmonella organisms invade through the intestinal wall of host, multiplying mainly in lymphoid tissues and resulting in bacteremia, while in gastroenteric type microorganisms normally do not cause general infection and the lesions are confined mainly to the intestine (Elkeles and Standfuss, 1931; Tulboch, 1939; Kojima and Hatta, 1942; Kuwahata, 1942; Kuwahata, 1943; Sutherland and Berger, 1944; Wilson and Miles, 1946; Edwards and Bruner, 1948; Uetake et al., 1948).

Though the above is a generally well-known fact, it has not been made clear as yet wherefrom the difference of infection type arises. It is also clear that infection generally depends upon the relationship between hosts and infecting agents; for example, $S$. typhi produces typhoid infection in man but not in other animals, while $S$. enteritidis is capable of producing infection in mice, but not in man.

However, when the host is restricted to a certain species, for example, to human beings, it seems reasonable to postulate that some difference may exist between infectious agents of different types of infection. On the other hand, recent advances in biochemistry have made clear that almost every type of life phenomenon is closely related with metabolism; for instance, muscle contraction depends upon phosphate metabolism (Engelhardt, 1946), and respiration and fermentation depend upon biological oxidation and reduction (Lardy, 1949;

1) 植竹久雄 - 2) 牧野利一, 3) 札幌医科大学微生物学教室 
Stumpf, 1954). Hence it seems possible that the types of bacterial infection may depend on the metabolism of bacteria and host animals. This has led the authors to the comparison of physiology of Salmonella species.

The outline of a part of the research along this line was reported in brief note (Uetake and Makino, 1954), and this paper will deal with a more detailed description.

\section{MATERIAL AND Methods}

Strains: Strains employed in this series of experiments were $S$. typhi H901W, S. paratyphi $A 1015$, S. paratyphi B 6617 , S. paratyphi B 8006, S. paratyphi $C$ "East Africa", S. paratyphi C "Hirschfeld", S. sendai 571, S. dublin 215, S. enteritidis 1891, S. bareilly 3213, S. moscow 27, S. cholerae suis, S. blegdam $\mathrm{Bl}_{3} \mathrm{~S}$, S. typhimurium 1406 , S. thompson 8, S. london 1446, and S. newport 563, all of which with the exception of one strain are international standard strains which were sent from F. Kauffman to the Enterobacteriaceae Committee of Japan, the donor. The one exception, S. blegdam

Table 1. Infection types of Salmonellas

\begin{tabular}{llcc}
\hline & & \multicolumn{2}{c}{ Infection types } \\
\cline { 2 - 3 } & & Typhoid or septicemic & Gastroenteric \\
\hline S. paratyphi A & + & - \\
S. typhi & + & - & $(+)$ \\
S. paratyphi B & + & \\
S. paratyphi $C$ & + & + \\
S. sendai & + & + \\
S. typhimurium & $(+)$ & + \\
S. cholerae suis & + & + \\
S. dublin & + & + \\
S. enteritidis & $(+)$ & + \\
S. bareilly & $(+)$ & ++ \\
S. moscow & $(+?)$ & + \\
S. blegdam & + & + \\
S. thompson & & + \\
S. london & & + \\
S. newport & $(+)$ & \\
\hline
\end{tabular}

(+) occasionally

$\mathrm{Bl}_{3} \mathrm{~S}$ is the strain isolated by Uetake and his collaborators (1948) in Hokkaido. The relationship of Salmonella types to infection types in man are shown in Table 1.

Bacterial suspensions: All these cultures were maintained on nutrient agar, $\mathrm{pH}$ 7.2-7.4. The cells grown on nutrient agar at $37^{\circ} \mathrm{C}$ for 18 hours were harvested and suspended in distilled water, washed thrice by centrifugation in distilled water, and finally resuspended in $\mathrm{M} / 20$ phosphate buffer of $\mathrm{pH} 7.2$, at an appropriate density by using Shimadzu photoelectric colorimeter (DF-II).

Manometry: Oxygen uptake was measured by conventional manometric technique, using the Warburg respirometer. Four-tenths ce of $\mathrm{M} / 4$ phosphate buffer of $\mathrm{pH} 7.2$, 0.5 cc of cell suspension, $0.4 \mathrm{cc}$ of $\mathrm{M} / 6$ substrates and $0.7 \mathrm{cc}$ of distilled water were 
kept in the main compartment of the Warburg flask. But when necessary, the substrate was , kept in the side arm until tipped into the main compartment. The center cup contained $0.3 \mathrm{cc}$ of $20 \% \mathrm{KOH}$ with $4.5 \mathrm{~cm}^{2}$ filter paper (Toyo No. 2) to absorb any carbon dioxide liberated during the oxidation. All experiments were carried at $30^{\circ} \mathrm{C}$, and the reaction was allowed to proceed for 1 hour.

The rate of glycolysis was determined manometrically by the Warburg respirometer, measuring the amount of carbon dioxide released from bicarbonate buffer by acid produced from glucose under anaerobic conditions.

\section{RESULTS}

No significant differences were observed between the two infection-type groups in the activity of oxidizing glucose, lactate and pyruvate, which are known as intermediates of glycolysis (Fig. 1).

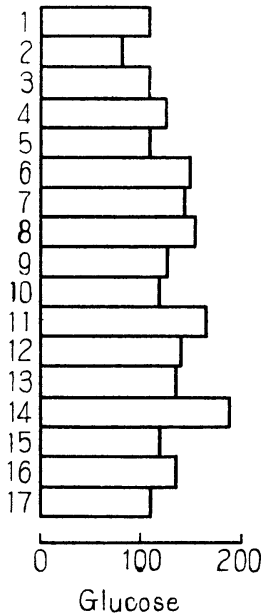

1: S. paratyphi $A$ 1015,

4: S. paratyphi $B 8006$,

6: S. paratyphi $C$ "Hirsch

9: S. enteritidis 1891,

12: S. cholerae suis,

15: S. london 1446,

* not observed
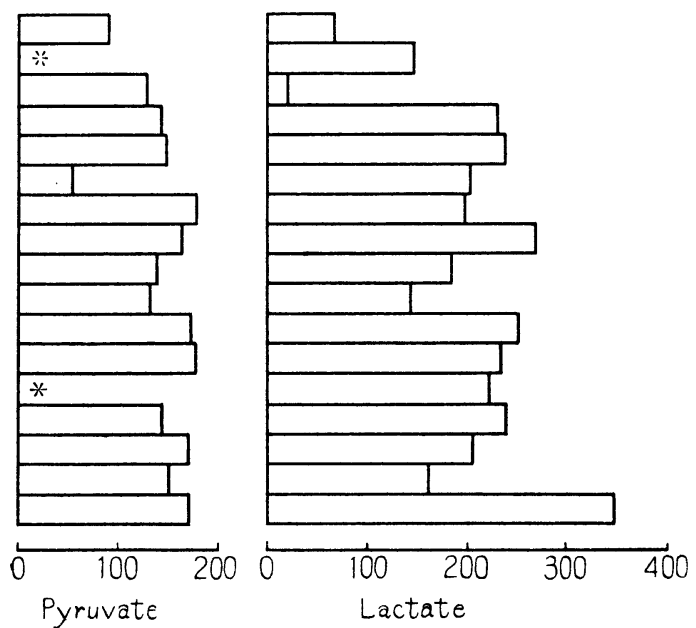

2: S. typhi H901W, 3: S. paratyphi B 6617, 5: S. paratyphi C "East Africa", 7: S. sendai 571, 8: S. dublin 215, 10: S. bareilly 3213, 11: S. moscow 27, 13: S. blegdam $\mathrm{Bl}_{3} \mathrm{~S}, \quad$ 14: S. thompson 8, 16: S. newport 563, 17: S. typhimurium 1406

Fig. 1. Comparison of $\mathrm{Qo}_{2}$ for oxidation of glycolytic intermediates

When one of the intermediates of respiration cycle $\left(\mathrm{C}_{4}\right.$-dicarboxylic acid cycle or tricarboxylic acid cycle), such as succinate, fumarate, malate or acetate was added to the suspension as substrate, certain significant differences were observed between the two bacterial groups. As shown in Fig. 2, the strains belonging to the typhoid type, showed a very low activity of oxidizing of these organic acids, whereas those of gasteroenteritis type showed a very high activity.

From the above mentioned results it was suggested that, between the two groups, while aerobic oxidation activity is different, fermentation activity is not different. To determine these points, the fermentation activity was estimated 


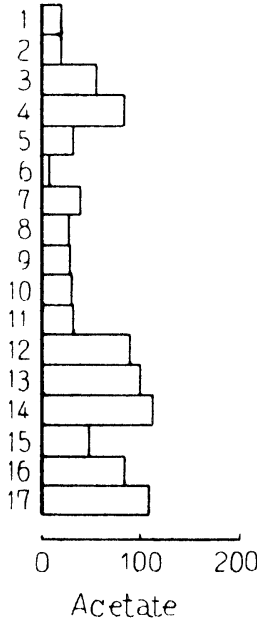

1: S. paratyphi $A$ 1015, 4: S. paratyphi $B 8006$, 6: S. paratyphi $C$ "Hirsch 9: S. enteritidis 1891, 12: S. cholerae suis, 15: S. london 1446,
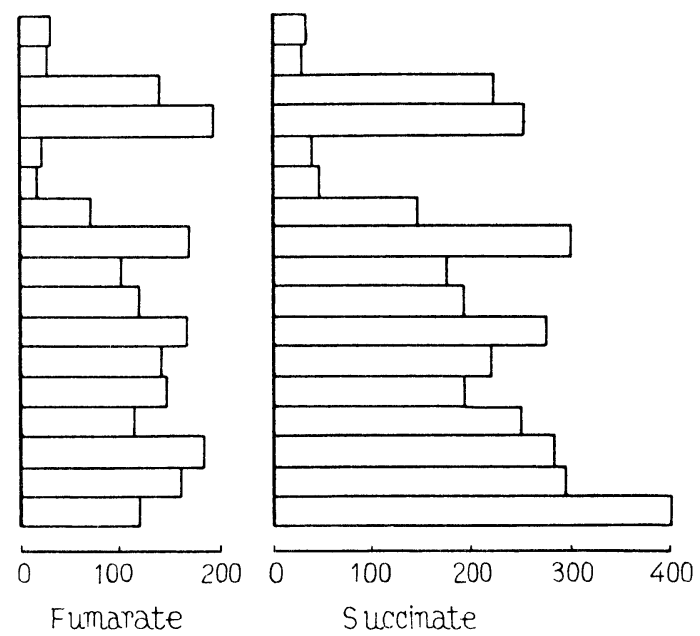

2: S. typhi H901W, 3: S. paratyphi B 6617, 5: S. paratyphi $C$ "East Africa", 7: S. sendai 571, 8: S. dublin 215, 10: S. bareilly 3213, 11: S. moscow 27, 13: S. blegdam $\mathrm{Bl}_{3} \mathrm{~S}, \quad 14$ : S. thompson 8, 16: S. newport 563, 17: S. typhimurium 1406

Fig. 2. Comparison of $\mathrm{Qo}_{2}$ for oxidation of TCA-cycle's Intermediates

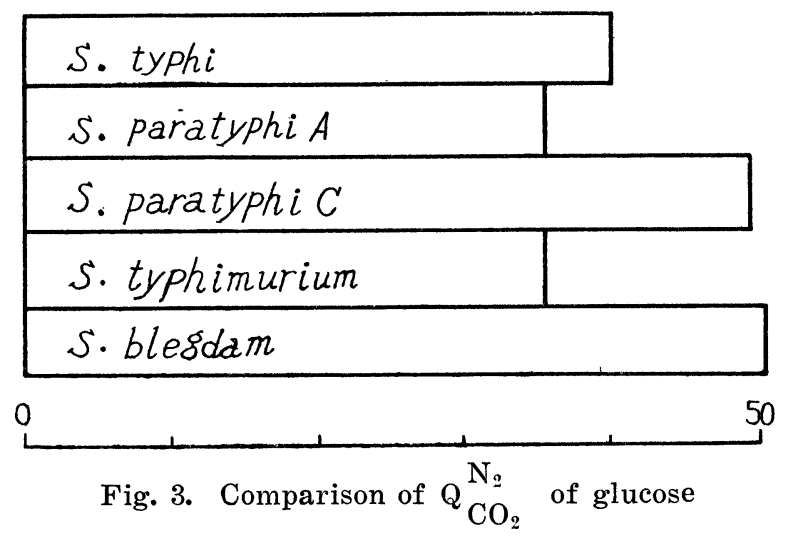

and compared with each other strains. As shown in Fig. 3, in acid production under anaerobic condition, significant difference was not noted.

To test the difference in oxidation activity between the two groups, the effect caused by the addition of succinate on acetate oxidation was examined, with the results as shown in Tables 2 and 3, Figs. 4(a) and (b). Fig. 4(a) shows the effect brought about by the addition of succinate in a high concentration and Fig. 4 (b) in a low concentration. When M/400 acetate was oxidized completly, approximately $206 \mu \mathrm{l}$ of oxygen was consumed and this amount was approximately the same as that consumed when succinate $(M / 30)$ was added. The only difference is in the time required for oxidation of acetate in its entire 
Table 2. Effect of acetic acid addition on succinic acid oxidation by Salmonella species

\begin{tabular}{l|c|c|c}
\hline Species & $\begin{array}{c}\text { Relative activity } \\
\text { of succinic acid } \\
\text { oxidation } \\
\text { (acetate=100) }\end{array}$ & $\begin{array}{c}\text { Calculated values } \\
\text { at time of } \\
\text { addition }\end{array}$ & $\begin{array}{c}\text { Observed values } \\
\text { at time of } \\
\text { addition }\end{array}$ \\
\hline S. typhi & 460 & 560 & 797 \\
S. paratyphi $A$ & 83 & 183 & 213 \\
S. typhimurium & 220 & 320 & 233 \\
S. blegdam & 194 & 294 & 213 \\
\hline
\end{tabular}

Table 3. Effect of acetic acid addition on dicarboxylic acid oxidation in S. typhi

\begin{tabular}{l|c|c|c|c}
\hline $\begin{array}{c}\text { Dicarboxylic } \\
\text { acid }\end{array}$ & $\begin{array}{c}\text { Relative activity } \\
\text { of dicarboxylic } \\
\text { acids oxidation } \\
\text { (acetate=100) }\end{array}$ & $\begin{array}{c}\text { Calculated } \\
\text { values at time } \\
\text { of addition } \\
\text { (a) }\end{array}$ & $\begin{array}{c}\text { Observed } \\
\text { values at time } \\
\text { of addition } \\
\text { (b) }\end{array}$ & b-a \\
\hline Succinate & 460 & 560 & 797 & 237 \\
Fumarate & 63 & 163 & 375 & 212 \\
Malate & 71 & 171 & 325 & 154 \\
Glutamate & 150 & 250 & 497 & 247 \\
Aspartate & 200 & 300 & 592 & 292 \\
\hline
\end{tabular}

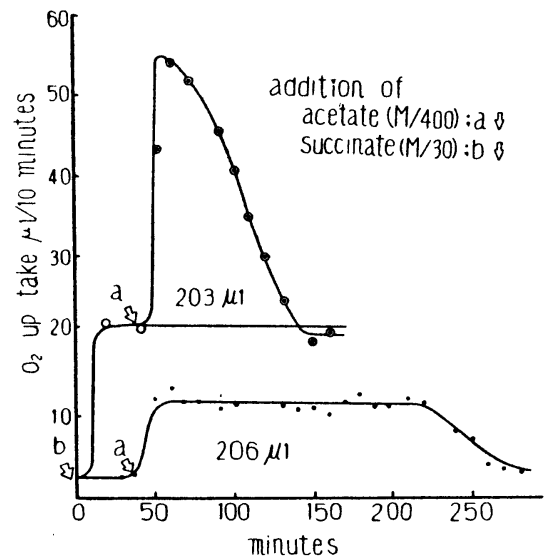

Fig. 4 (a). Effect of addition of succinic acid on the acetic acid oxidation rate in Salmonella typhi

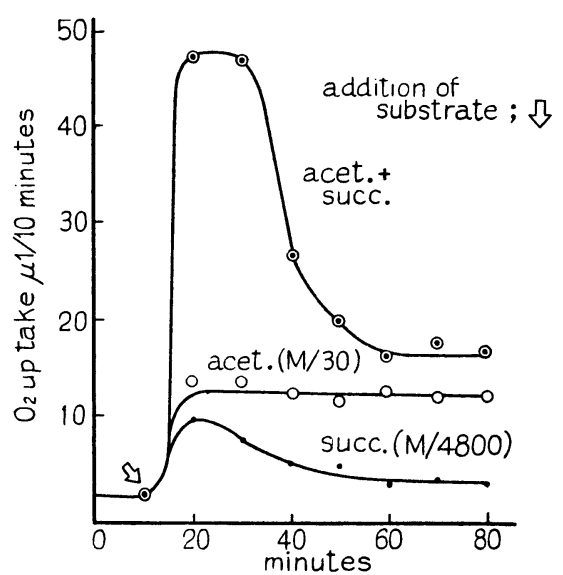

Fig. 4 (b). Effect of addition of succinic acid in a low concentration on the acetic acid oxidation rate in Salmonella typhi

amount; with acetate alone, it required approximately 210 minutes, while when succinate was added, approximately 100 minutes was required. Thus, it can be said that oxidation of acetate was accelerated by succinate.

When succinate in the low concentration was added to the acetate oxidation 
system, as shown in Fig. 4(b) a larger amount of oxygen was consumed as compared to that required for complete oxidation of succinate alone. And the increase of oxygen consumption continued until succinate was completely exhausted. These findings also indicate that oxidation of acetate was accelerated by succinate. But it should be pointed out that the pattern of acceleration of acetate oxidation by succinate is somewhat different from that observed in animal tissues, in that a small amount of succinate was unable to maintain a high level of accelerated oxidation of acetate as shown in Fig. 4(b). It has been said of animal tissues that when once accelerated the high level of acetate oxidation continues until the acetate is exhausted (Lardy, 1949).

In short, it can be said that in organisms causing typhoid type of infection such as $S$. typhi and $S$. paratyphi $A$, acetate oxidation was accelerated by addition of succinate while no acceleration was observed in organisms causing gastroenteritis type of infection such as $S$. typhimurium and S. blegdam (Tables 2 and 3$)$.

\section{Discussion}

From the above experimental data, the following points are noted.

1) According to $\mathrm{Qo}_{2}$ with glucose, pyruvate and lactate, and that with acetate, succinate and fumarate, the strains employed can be divided into two distinct groups.

2) As to $\mathrm{QO}_{2}$ with acetate-succinate-fumarate, very low values were obtained in the strains of typhoid type infection group such as $S$. typhi, S. paratyphi $A$ and $S$. paratyphi $C$, while much higher ones in strains causing gastroenteritis type infection, such as S. typhimurium, S. cholerae suis, S. thompson, S. newport, S. blegdam and S. london.

3) As to $\mathrm{Qo}_{2}$ with glucose-pyruvate-lactate, significant difference was not observed among the type strains, irrespective of infection types.

4) $S$. paratyphi $B$ showed a metabolic pattern similar to that shown by gastroenteritis type strains, though it usually causes typhoid infection in man.

The most important difference observed between the two infection type groups is point (2) as listed above. But in regards to point (2), the permeability of cell membrane should be taken into consideration, since intact cell suspensions were employed. Recent studies on bacterial physiology have shown that in some bacteria the intracellular biochemical reactions may be limited by the permeability of cell membrane to substrates added extracellularly (Stone and Wilson, 1952; Fukui and Sandemark, 1952; Krebs et al., 1952; Lara and Stokes, 1952; Gerhardt et al., 1953). When the permeability is low, the oxygen consumption by intact cells does not always reflect the real velocity of reactions by oxidative enzyme but rather it may probably reflect only the velocity of transmission of substrate through the cell membrane. Therefore, unless the problem of the permeability is solved, it is impossible to conclude that the infection types depend upon patterns of bacterial respiration, since there remains a possibility 
that the low activity of oxidizing dicarboxylic acids by organisms causing typhoid type infection might be due to low permeability of their cell membranes. However, it can be said that the stimulation of the rate of acetate oxidation by addition of dicarboxylic acid, suggests the intracellular existence of enzymes in sufficient quantities to catalyze the dicarboxylic acid oxidation which participates in acetate metabolism. Although the problem of permeability is now. under study, the increase of oxygen consumption rate by simultaneous addition of acetate and dicarboxylic acid suggests that there exists a fundamental difference between the two groups in respiratory patterns, especially and probably in $\mathrm{C}_{2}$ unit oxidizing system. This also suggests that the difference is not only quantitative but also qualitative and that some difference may exist in the mechanism of acetate oxidation.

The reason why in the organisms of gastroenteritis type acetate oxidation was not accelerated by addition of succinate (Tables 2 and 3), has not been made clear in the present study, but one possible explanation to it might be that, if the organisms had the high activity of Thunberg-Knoop condensing enzyme which catalyses condensation of two molecules of acetate into succinate, the addition of succinate would have no effect on acetate oxidation.

As pointed out in (4) $S$. paratyphi $B$ showed an intermediate type of behavior. Thus, it showed high activity in dicarboxylic acid oxidation, though it usually gives rise to a typhoid type of infection in man. This finding may have some possible correlation to the fact that $S$. paratyphi $B$ sometimes shows gastroentertis in initial stage of infection and that even in typhoid type of infection the incubation period is relatively short as compared with that in infection of $S$. typhi or $S$. paratyphi $A$ (Elkeles and Standfuss, 1931; Wilson and Miles, 1946). S. sendai is also an agent causing a septicemic or typhoid infection but showing a respiratory metabolic pattern similar to that of gastroenteritis type of Salmonella. In this case, however, it should be pointed out that the activity of oxidizing TCA cycle intermediates was relatively low as compared with that of gastroenteritis type organisms.

$S$. blegdam, showing a respiratory pattern of gastroenteric type organisms, is generally known to cause predominantly a septicemia, but in this case it should be recalled that usually it does not cause a typhoid infection but in many cases it causes a suppurative inflammation in various organs or tissues.

In Shigella dysenteriae, Shigella flexneri and Escherichia coli, all of which have been known to infect the intestinal tracts and hardly ever to invade the blood stream, have been found to present a respiratory pattern similar to that shown by Salmonellas of gastroenteritis type (unpublished data). And furthermore $S$. typhi $\mathrm{R}_{2}$, rough type of typhoid bacillus, also showed a respiratory pattern of gastroenteritis type (unpublished data), in contrast to smooth type of the organism.

As for the $\mathrm{C}_{4}$-dicarboxylic acid dehydrogenase in $S$. typhi and in $S$. paratyphi $A$, similar results were reported by Fukumi and his collaborators (1952; 
1953). They reported that with $S$. typhi the tri- or dicarboxylic acid cycle may not operate regularly, but a certain part of the Krebs cycle might be revived by an adaptation procedure. And in addition it should be mentioned that only 6 strains out of 38 employed were adaptated to citric acid successfully and that even in the case of malate adapted strains, acetate could not be utilized. The $901 \mathrm{~W}$ strain of $S$. typhi was also employed by Fukumi et al. with the results similar to the authors' findings. Experiments with $S$. paratyphi $A$ along the same line showed that 10 strains out of 14 were capable of being adapted to citric acid and 2 were adapted to succinic acid. Fukumi's findings indicate the possibility of adaptation of $S$. paratyphi $A$ to dicarboxylic acids, but it may be slightly premature to draw a general conclusion from the above until further studies are made by using many freshly isolated strains, since even $S$. typhi, when transformed to rough type, showed a respiratory pattern similar to that in gastroenteric type of Salmonellas, and since, according to Fukumi et al., there exist certain strains incapable of being adapted and in addition even succinate adapted strains cannot utilize acetate as seen in $S$. typhi.

In short, it has been revealed that a certain correlation may exist between the infection types and the respiratory patterns in Salmonellas. However, the correlation should not be extended as a general rule to other combinations of hosts and parasites, since it is well known that infection types generally depend upon host-parasite relationships as already pointed out in the introduction of this paper.

Before finishing this manuscript, the report by Shrivasta, Agarwala and Bhantnagar (1954) should be taken into consideration, in which, in contact to the authors' findings, the oxygen uptake with succinate was not so small as compared to that with lactate or pyruvate. The reason of the difference between the two findings is not exactly clear, but the authors are of opinion that the high oxygen uptake in the above mentioned researchers' work might be due to insufficient washing of cells, since endogenous oxygen uptake in 60 minutes seems rather high and the difference of oxygen uptake between 60 and 120 minutes seems rather small.

\section{SUMMARY}

Activities of oxidation and fermentation of the two groups of Salmonella species which are different in infection types in man, typhoidal and gastroenteric, were compared.

In glycolysis and oxidation of glycolytic intermediates, no significant differences were observed, while in the oxidation of the TCA cycle intermediates, marked differences were observed.

The relations among infection types, the respiratory patterns, and the permeability of cell membrane were discussed. 


\section{REFERENCES}

Edwards, P.R. and Bruner, D.W. (1948): The genus Salmonella; Its occurrence and distribution in the United States. Kentucky Agr. Exper. Station Bull., 525.

Elkeles, G. and Standfuss, R. (1931): Handbuch der pathogenen Mikroorganismen, 3, 1585-1826.

Engelhardt, V.A. (1946): Adenosinetriphosphatase properties of myosin. Advances Enzymol., 6, 147-191.

Fukui, G.M. and Sandemark, P. J. (1952): Evidence for tricarboxylic acid cycle in Corynebacterium creatinovorans. J. Bact., 64, 887-888.

Fukumi, F., Sayama, E. and Nakaya, R. (1952): $\mathrm{C}_{4}$-dicarboxylic acid cycle and Salmonella typhi. Jap. J. M. Sc. \& Biol., 5, 487-492.

Fukumi, F., Sayama, E. and Nakaya, R. (1953): Nutritional requirements of Salmonella paratyphi and its terminal respiratory pattern. Jap. J. M. Sc. \& Biol., 6, 25-31.

Gerhardt, P., MacGregor, D.R., Marr, A.G., Olson, C.B. and Wilson, J.B. (1953) : The metabolism of Brucellae: the role of cellular permeability. J. Bact., 65, 581-586.

Kojima, S. and Hatta, S. (1941) : [Bacteria responsible for food-poisoning]. Kanehara \& Co. Ltd., Tokyo (text in Japanese).

Krebs, H.A., Gurin, S. and Eggleston, L.V. (1952): The pathway of oxidation of acetate in baker's yeast. Biochem. J., 51, 614-628.

Kuwahata, M. (1942): [Studies on the paratyphoid bacilli isolated in China. 2. Typing of strains isolated in Middle and North China in 1941]. "Nagasaki Igakukai Zasshi", 20, 479-492.

Kuwahata, M. (1943) : [Studies on the paratyphoid bacilli isolated in China. 3. Typing of the strains isolated in Manchuria in 1941, and review of distribution of Salmonella in China]. "Nagasaki Igakukai Zasshi”, 20, 2278-2292.

Lara, J. J. S. and Stokes, J. L. (1952) : Oxidation of citrate by Escherichia coli. J. Bact., 63, 415-420.

Lardy, H.A. (1949): Respiratory Emzymes, Burgess Publishing Company, Minneapolis.

Shrivastava, G.C., Agarwala, S.C. and Bhatnagar, S.S. (1954): Studies on the oxidative metabolism of Salmonella typhosa in relation to antigenicity and virulence. Enzymologia, 1\%, 41-46.

Stone, R. W. and Wilson, P.W. (1952) : Respiratory activity of cell-free extracts from Azotobacter. J. Bact., 63, 605-617.

Stumpf, P.K. (1954): Glycolysis. Chem. Pathways Metabol., 1, 67-108.

Sutherland, P.L. and Berger, F.M. (1944): A milkborne outbreak of gastroenteritis due to Salmonella dublin. Brit. M. J., 1, 488.

Tulboch, W.J. (1939): Observations concerning bacillary food infection in Dundee during the period 1923-1938. J. Hyg., 39, 324-333.

Uetake, H., Odani, T., Matsumiya, M. and Kogo, T. (1948) : [S. blegdam: A case of typhoid-like infection]. "Shin-rinsho", 2, 4-6.

Uetake, H. and Makino, T. (1954) : [Comparative studies on the relationship between infection types and metabolic patterns in Salmonella]. Med. \& Biol., 30, 160-163.

Wilson, G.S. and Miles, A.A. (1946) : Topley and Wilson's principles of bacteriology and immunity, 1, 3rd Ed., pp. 702-749, Edward Arnold \& Co., London. 